\title{
PERAN POLISI HUTAN DALAM MENANGGULANGI PEMBALAKAN LIAR/ILLEGAL LOGGING DALAM KAWASAN HUTAN DI KABUPATEN JEMBRANA PROVINSI BALI
}

\author{
I Made Adi Endra Supardi, Anak Agung Sagung Laksmi Dewi, Luh Putu Suryani \\ Fakultas Hukum Universitas Warmadewa, Denpasar-Bali, Indonesia
}

\begin{abstract}
Abstrak
Hutan harus dikelola dengan baik agar fungsi dan manfaatnya tetap terjaga. Salah satu masalah yang terkait dibidang kehutanan yaitu banyaknya praktek pembalakan liar disejumlah provinsi di Indonesia. Pemberantasan Pembalakan Liar pada Undang-Undang Republik Indonesia Nomor 18 tahun 2013 tentang pencegahan dan pemberantasan Perusakan Hutan. Penelitian ini bertujuan untuk mngetahui tugas dan peranan Polisi hutan didalam mencegah pembalakan liar dikawasan hutan Kabupaten Jembrana dan menaganalisis faktor hambatan Polisi hutan dalam mencegah pembalakan liar dikawasan hutan Kabupaten Jembrana Provinsi Bali. Penelitian ini menggunakan metode empiris dengan pendekatan perundang-undangan. Data yang digunakan adalah data primer dan sekunder yang diperoleh melalui wawancara dan dokumentasi. Data yang diperoleh kemudian dianalisis melalui desriptif kualitatif. Hasil penelitian menunjukkan bahwa Polisi kehuhutanan berperan untuk mengawasi pelaksanaan setiap kegiatan yang menimbulkan terjadinya kerusakan di kawasan hutan Kabupaten Jembrana. Faktor yang menjadi hambatan dalam melakukan peran polisi hutan mencegah pembalakan liar di Kawasan Hutan Kabupaten Jembrana yaitu faktor medan, sarana dan peralatan, keikhlasan, perduli dan tegas berkomitmen, faktor jumlah personel, cara baru kejahatan, dan faktor warga sekitar. Polisi hutan harus mengikutsertakan warga disekitar hutan dalam upaya mencegah pembalakan liar mengingat kewajiban menjaga pelestarian hutan tidak hanya tanggung jawab pemerintah saja akan tetapi juga tanggung jawab dari seluruh warga penyanding hutan khususnya di Kabupaten Jembrana.
\end{abstract}

Kata Kunci: Tugas Polisi Hutan; Pembalakan Liar; Penanggulangan Kawasan Hutan

\begin{abstract}
Forests must be managed properly so that their functions and benefits are maintained. One of the problems related to the forestry sector is the large number of illegal logging practices in a number of provinces in Indonesia. Eradication of Illegal Logging in Law of the Republic of Indonesia Number 18 of 2013 concerning the prevention and eradication of forest destruction. This study aims to determine the duties and roles of forest rangers in preventing illegal logging in the forest area of Jembrana Regency and to analyze the obstacle factors of forest rangers in preventing illegal logging in the forest area of Jembrana Regency, Bali Province. This study uses an empirical method with a statutory approach. The data used are primary and secondary data obtained through interviews and documentation. The data obtained were then analyzed through qualitative descriptive. The results showed that the Forestry Police had a role to supervise the implementation of every activity that caused damage to the forest area of Jembrana Regency. Factors that become obstacles in carrying out the role of forest rangers in preventing illegal logging in the Jembrana Regency Forest Area are terrain, facilities and equipment, sincerity, concern and firm commitment, the number of personnel, new methods of crime, and factors of local residents. Forest rangers must involve residents around the forest in an effort to prevent illegal logging considering that the obligation to conserve forests is not only the responsibility of the government but also the responsibility of all forest border residents, especially in Jembrana Regency.
\end{abstract}

Keywords: Forest Area Management; Illegal Logging; Ranger Duties

\section{PENDAHULUAN}

Provinsi Bali merupakan satu dari provinsi di Indonesia yang mempunyai hutan paling sedikit. Walau demikian di Provinsi Bali khususnya di Kabupaten Jembrana terjadi kerusakan di kawasan hutan yang amat parah, kerusakan hutan di Kabupaten Jembrana kebanyakan disebabkan karena pembalakan liar. Pembalakan liar ialah kegiatan menebang pohon yang tidak sah, tidak ada izin, tidak melalui prosedur, atau melawan hukum. (Khakim, 2005). dampak pembalakan liar di kawasan hutan Jembrana ialah punahnya berbagai varian alam dan hayati, pembalakan liar yang semakin marak pastinya akan merusak keasrian hutan dan mengancam tumbuh kembangnya flora dan fauna. 
Bila kegiatan pembabatan pohon terus menerus dilakukan sudah dipastikan akan menimbulkan bencana alam, Pepohonan yang semakin sedikit bila hujan dengan curah tinggi tentu akan mengakibatkan erosi karena sedikitnya menyerap air, sehingga mengecilnya aliran air sungai yang menimbulkan kekeringan dihilir, berdampak bagi masyarakat. Seperti diketahui hutan sebagai salah satu fungsinya sebagai tempat cadangan Air. Rusaknya permukaan Tanah bila fungsinya tidak sesuai dengan aslinya, sehingga hutan tidak akan optimal untuk menjalankan fungsinya menjaga lapisan tanah.

Herman Hidayat, (2015) perlunya menjaga dan melestarikan kawasan hutan konservasi Cyclop konservasi, hal ini didasarkan atas pertimbangan strategis cyclop yang difungsikan sebagai kawasan tangkapan air, sumber hidrologi untuk pasokan air minum untuk masyarakat.

Pembalakan liar di kawasan hutan yang terjadi belakangan ini ialah kasus dikawasan hutan Bali barat. Polisi Kehutanan menangkap pelaku farul ahwad belajam (35) asal Buleleng, diketahui truk mengangkut 388 batangan pohon sonokeling terdiri dari 160 batang pohon adalah hasil kebun yang telah dilengkapi dengan dokumen resmi pengangkutan dan sisanya sebanyak 228 batang pohon kayu adalah illegal yang diperoleh dari kawasan hutan Bali Barat. Penebangan memberi dampak yang sangat merugikan masyarakat sekitar, bahkan masyarakat dunia. Kerugian yang diakibatkan oleh kerusakan hutan tidak hanya kerusakan secara nilai ekonomi, akan tetapi juga mengakibatkan hilangnya nyawa yang tidak ternilai harganya (Bawono \& Mashdurohatun, 2011). Hutan sebagai sumber kehidupan dan salah satu bagian kekayaan alam yang dianugerahkan Sang Pencipta Alam. Hutan adalah "Jumlah pohon atau tumbuh-tumbuhan yang hidup pada wilayah yang lumayan luas, hingga suhu, lembab, sinar, udara dan lainnya tidak lagi menentukan lingkungan sendiri, dengan demikian pengaruh oleh tumbuhan atau pepohonan baru asalkan muncul pada wilayahnya yang luas dan tumbuh lumayan lebat (horizontal dan vertikal)" (Anas \& Marlina, 2018).

Penurunan fungsi kawasan hutan terjadi dimana-mana diakibatkan oleh ulah manusia itu sendiri dengan dalih memenuhi kebutuhan perekonomian dengan melakukan tindakan illegal terhadap kawasan hutan seperti merusak hutan seperti kegiatan pembalakan liar, penebangan pohon tidak berizin dan berkebun tanpa izin yang tentunya mengakibatkan rusaknya lingkungan hidup dan rusaknya kehidupan sosial budaya masyarakat itu sendiri bahkan meningkatkan Pemanasan Global yang telah menjadi isu Nasional, dan Internasional. Perusak hutan bahkan dikatagorikan menjadi kejahatan luar biasa, terorganisasi, yang dilakukan dengan modus baru yang canggih, terorganisasi, terstruktur terutama kejahatan pembalakan liar yang banyak menimbulkan kerugian Negara (Barus \& Alvi Syahrin, 2015).

Kurangnya lapangan kerja dan faktor kmiskinan warga memicu perbuatan illegal longging seperti melakukan, selanjutnya keterlibatan aparat penagak hukum sehingga menyebabkan adanya main mata atau KKN diantara aparat dan palaku illegal logging (Basir, 2016). Menurut Suhaeni et al., (2015) kerusakan hutan lindung Balang Lajangnge khususnya penebangan pohon dan kebakaran hutan atau pencurian kayu tanpa izin telah ditindaklanjuti oleh pihak polisi kehutanan dan diharapkan diberikan sanksi kepada pelaku yang sewajarnya, serta dibutuhkan kerjasama masyarakat untuk memanimalisir kebakaran hutan, pencurian kayu tanpa izin, karena sebagian masyarakat belum menganggap serius tentang pemberitahuan penebangan pohon tanpa izin, dikarenakan sosialisasi yang belum merata

Penelitian ini bertujuan untuk mengetahui peran Polisi kehuhutanan dalam mencegah Pembalakan liar di kawasan hutan Kabupaten Jembrana dan menganalisis faktor penghambat yang dihadapi Polisi hutan dalam mencegah kejahatan Pembalakan liar di Kabupaten Jembrana.

\section{METODE PENELITIAN}

Jenis penelitian yang digunakan adalah penelitian hukum empiris ialah metode penelitian hukum yang gunanya untuk melihat langsung secara nyata penerapan hukum dimasyarakat. Data yang digunakan adalah data primer yaitu data yang digali langsung oleh peneliti yang didapat dari lapangan dengan cara wawancara langsung dengan pihak- pihak yang berkaitan kedinasan Kehutanan dan Polisi Kehutanan di kabupaten Jembrana dan data sekunder adalah yang diperoleh dari sumber-sumber hukum maupun buku lain yang terkait, perundang-undangan, surat kabar dan majalah. Data-data yang sudah terkumpul data diolah dan di analisis dengan secara kualitatif deskriptif (Sugiyono, 2013). 


\section{HASIL DAN PEMBAHASAN}

\section{Peran Polisi Kehutanan dalam Menanggulangi Pembalakan Liar di kawasan Hutan Jembrana Bali}

Pengertian Polisi Kehutanan diatur dalam Pasal 1 Ayat 2 Permen (peraturan menteri) PANRB (pendayagunaan aparatur negara dan reformasi birokrasi) Nomor 17 Tahun 2011 tentang jabatan fungsional polisi hutan yaitu : Polisi Hutan disebut juga jaga wana adalah Pegawai dalam lingkungan instansi Kehutanan yang fungsi dengan sifat kerjanya melakukan kegiatan melindungi kawasan hutan yang oleh diatur Perundang-undangan dikasi wewenang sebagai polisi khusus yang membidangi kehutanan dan seluruh yang berkaitan dengan kehutanan hayati ekosistem dan sember data daya alamnya.

Pada Pasal 1 diatur di angka 2 PP No. 45 Tahun 2004 tentang Perlindungan Hutan adalah: Oleh kuasa Undang-undang dikasi kewenangan polisi khusus yang membidangi kehutanan sesuai sifat dan pekerjaannya. Pada pasal 1 angka 15 undang-undang Nomor 18 Tahun 2013 yaitu: melakukan usaha melindungi hutan yang oleh kuasa Perundang-undangan dikasi kewenangan khusus yang membidangi kehutanan.

Dasar Hukum Polisi Kehutanan

Sesuai Undang-undang No. 5 tahun 1967 tentang pokok-pokok kehutanan dalam pasal 18 ayat 1 adalah: untuk memenuhi kegiatan perlindungan bagi hutan yang lestari oleh sebab itu diberi kewenangan polisi khusus. Peran dan tugas polisi hutan atau yang disebut jaga wana di atur pada pasal 16 Undang-undang No. 5 Tahun 1967 tentang pokok kehutanan di ayat 1 yaitu :

a) Menyelenggarakan kunjungan kelapangan wilayah hutan

b) Mengecek surat-surat atau dokumen bersangkutan terhadap hasil dari hutan dan dikasi wewenang oleh pejabat untuk diperiksa

c) Menerima aduan dari masyarakat telah terjadi kejahatan atas kawasan hutan.

d) Menyelidiki dan mencari bukti-bukti telah terjadinya kejahatan dibidang kehutanan.

e) Dalam kegiatan kunjungan dapat pelaku kejahatan terhadap kawasan hutan wajib menyerahkan kepada penyidik Polri.

f) wajib membuat laporan bila ada kejahatan dikawasan hutan.

Pembalakan liar atau pembabatan liar yang ada kaitan dengan kegiatan kehutanan dan kekayaan alam hayati, dan juga industri yang ada kaitan pada hutan dan hasilnya pohon maupun non pohon (Tacconi, 2007). Kegiatan ini meliputi tindakan yang melanggar hak atas lahan hutan, dalam hal ini pembalakan liar atau pembabatan liar jelas kegiatan yang tidak sah menurut hukum dan merusak kelestarian kawasan hutan.

Merusak hutan adalah kegiatan, melanggar, atau kegiatan tidak sah melalui kejahatan tanpa ada izin dari polisi hutan atau pemerintah jelas melanggar peraturan dan perundang-undangan dengan cara pembabatan liar akan dikenakan sanksi pidana. Sesuai pemantauan dan tindakan yang ditemukan dilokasi terjadi suatu perkara, dimana dilakukan pembalakan liar secara tidak sah, melihat kawasan hutan yang sangat luas dan jumlah personel polisi hutan yang tidak sebanding dengan luasan wilayah, ini bisa dilakukan dengan menjalin suatu kerja sama dengan warga yang bersandingan langsung dengan kawasan hutan guna bersama-sama menjaga kelestarian hutan. Hukum kehutanan adalah rangkaian kaidah hukum/norma hukum baik tidak tertulis maupun yang tertulis. yang tumbuh dan dipertahankan di rangkaian hutan dan kehutanan (Mar, 1993).

\section{Faktor Penghambat Polisi Kehutanan dalam Menanggulangi Pembalakan Liar}

Pasal 56 ayat (1) UURI Nomor 18 tahun 2013 yaitu: badan atau kelembagaan yang menangani pencegahan dan pemberantas pengerusak hutan pada Pasal 54 ayat (1) berperan:

a) Melakukan kegiatan menyelidiki dan menyidik terhadap kejahatan terhadap hutan

b) Melakukan administrasi penyidikan dan penyelidikan terhadap perkara kejahatan kehutanan.

c) Melakukan sosialisasi untuk kelestarian hutan.

d) Melakukan dan menjalakan sebagai informan tentang mencegah dan berantas pengerusak hutan yang terintegritas.

e) Mengoptimalkan masyarakat guna upaya mencegah dan memberantas pengerusak hutan.

f) menjalin suatu kemitraan dan koordinasi antara lembaga penegak hukum lainnya dalam memberantasan pengerusak hutan. 
Salah satu faktor yang menghambat tugas kepolisian dalam mencegah pembalakan liar kurangnya koordinasi antara polisi hutan dan penegak hukum lainnya, koordinasi antara polisi hutan dengan penegak hukum lainnya sangatlah penting dalam memproses terhadap kejahatan pembalakan liar (Erbabley, 2013). Semua pihak yang berkaitan dengan penegak hukum harus ikut terlibat dalam proses mencegah dan memberantas pengerusak hutan, yang kedua begitu luas sehingga tidak maksimalnya dalam menjalakan tugas atau mengawasi wilayah hukumnya, faktor sarana juga perlu ditingkatkan dan diperlengkap prasarana supaya lebih memudahkan polisi hutan dalam menjalakan tugasnya.

Polisi hutan dibutuhkan keseriusan dalam menjalakan tugas dan memegang erat prinsip keadilan dalam menjalakan tugas dan fungsinya, disisi lain ketegasan petugas dalam menindak setiap ada kegiatan yang melanggar, merusak kelestarian hutan dikawasan hutan Kabupaten Jembrana. Seiring waktu modus operandi kejahatan semakin canggih seiring kemajuan teknologi polisi kehutan berperan sangat penting dalam membaca modus-modus kejahatan, pendekatan kepada masyarakat di sekitar hutan dan menjalin kerja sama untuk bersama-sama menjaga dan mencegah adanya kerusakan di kawasan hutan.

Berdasarkan peraturan dan perundang-undangan Penerapan sanksi bagi tindak kejahatan terhadap kawasan hutan berdasarkan pada Pasal 82 ayat (1), ayat (2) dan ayat (3). Undang-undang Republik Indonesia tahun 2013. Pasal 82 ayat (1) seseorang degan sengaja melakukan kegiatan menebang pohon di dalam kawasan hutan tanpa izin dan tidak sah, Dipidana 5 (lima) tahun penjara dan pidana denda Rp. 2.500.000.000.,- (dua miliar lima ratus juta rupiah). Dalam pasal 82 ayat (2) orang atau perorangan yang berada dekat dengan wilayah kawasan hutan atau disekitaran hutan, Dipidana paling lama 2 (dua) tahun penjara dan denda Rp. 500.000.000.,- (lima ratus juta rupiah). Sedangkan di ayat (3) dengan berKorporasi kegiatan kejahatan terhadap kawasan hutan, Dipidana paling lama 15 (lima belas) tahun penjara dan denda paling banyak Rp. 15.000.000.000.,-(lima belas miliar rupiah).

\section{SIMPULAN DAN SARAN}

\section{Simpulan}

Berdasrkan analisis data dapat disimpulkan bahwa Pembalakan liar adalah satu dari masalah yang dihadapi pemerintah dibidang kehutanan yang harus cepat diselesaikan permasalahannya sebelum dampak dari pembalakan liar ini semakin hari semakin besar kerugian bagi Negara dan masyarakat. Maka dari itu untuk mencegah kejahatan pembalakan liar polisi hutan harus diberikan fasilitas yang memadai untuk mempermudah menjaga keutuhan kawasan hutan, perlunya penambahan petugas Polisi hutan atau Jagawana, dilakukan kunjungan/patroli ke wilayah hukumnya setiap hari dengan jumlah personel paling sedikit 2 (dua) personel Polisi Jagawana, dilaksanakan tindakan preventif dan sosialisasi kepada masyarakat terhadap pentingnya menjaga kelestarian hutan dan mencegah terjadinya pembalakan liar, yang kedua Faktor penghambat dalam melaksanakan tugas dan peran dari polisi Jagawana mencegah pembalakan liar di Kabupaten Jembrana adalah yaitu wilayah yang luas, sarana dan peralatan, keikhlasan, perduli dan tegas berkomitmen, jumlah personel yang tidak seimbang dengan luasan wilayah hukumnya, warga sekitar yang tidak mau bekerja sama.

\section{Saran}

Adapun yang disarankan peneliti yaitu dalam hal kejahatan tindak pidana pembalakan liar seharusnya menjadi tanggung jawab semua pihak baik dari pemerintah serta semua lapisan masyarakat ikut serta karena bila hal ini terus menurus dilakukan maka hutan di Indonesia khususnya di Kabupaten Jembrana akan sedikit jelas berpengaruh pada kehidupan masyarakat di kabupaten Jembrana tentunya, yamg kedua Polisi hutan atau Jaga wana dalam menjalakan tugas dan perannya dengan sangat serius untuk menjadi garda terdepan dalam suatu peristiwa kejahatan pengerusak hutan jangan ikut serta menjadi actor atau pelaku dari kejahatan pembalakan liar, ketegasan polisi kehutanan dalam menindak tindak pidana pembalakan liar harus sesuai dengan peraturan dan undang-undang tentang kehutanan. Oleh karena itu sangat diperlukannya dukungan dari pemerintah pusat dan daerah mengoptimalkan peran dan tugas dari polisi hutan dan peran dari masyarakat 


\section{DAFTAR PUSTAKA}

Anas, A., \& Marlina, M. (2018). Analisa Yuridis Penyidikan Tindak Pidana Illegal Logging oleh Polres Tapanuli Tengah. Jurnal Mercatoria, 11(1), 61-71.

Barus, R. M., \& Alvi Syahrin, S. A. (2015). Pertanggungjawaban Pidana Illegal Logging (Pembalakan Liar) Sebagai Kejahatan Kehutanan. USU Law Journal, 3(2), 106-114.

Basir, M. A. (2016). Upaya Pemerintah Dalam Menangani Illegal Loging (Studi Pada Uptd Kehutanan Kecamatan Kulisusu Kabupaten Buton Utara). Jurnal Studi Kepemerintahan, 1(2), 38-47.

Bawono, B. T., \& Mashdurohatun, A. (2011). Penegakan Hukum Pidana di Bidang Illegal Logging Bagi Kelestarian Lingkungan Hidup dan Upaya Penanggulangannya. Jurnal Hukum, 26(2), 590-611.

Erbabley, A. N. J. (2013). Fungsi Koordinasi Penyidik Polisi dengan Penyidik Pegawai Negeri Sipil Kehutanan dalam Proses Penyidikan Tindak Pidana Pembalakan Liar. Jurnal Ilmu Hukum Legal Opinion, 3(1), 1-9.

Hidayat, H. (2015). Pengelolaan Hutan Lestari. Pustaka Obor Indonesia.

Khakim, A. (2005). Pengantar Hukum Kehutanan Indonesia. PT Citra Aditya Bakti.

Mar, I. S. Al. (1993). Pengukuhan Hutan dan Aspek-aspek Hukum. Sinar Grafika.

Sugiyono. (2013). Metode Penelitian Pendidikan Pendekatan Kuantitatif dan Kualitatif. Alfabeta.

Suhaeni, Azikin, R., \& Razak, A. R. (2015). Peran Polisi Kehutanan dalam Menjaga Kawasan hutan lindung Balang Lajange di Desa Talle Kecamatan Sinjai Selatan Kabupaten Sinjai. 1(1), 41-51.

Tacconi, L. (2007). Law enforcement livelihoods and the timbertrade. Susanne Harris. 31ffffe57f13/368290.pdf 